JOSEPHINE ROWE

\title{
THE VENDING MACHINE AT THE END OF THE WORLD
}

He moved into a hotel with my name and called most nights from the payphone in the hallway. Before that he used to call from a phone box on the corner of Second Avenue and Pine, and I could always hear sirens in the background and drunks shouting at each other. Fuck you motherfuckers, I can fly. That was when he was sleeping in a park at night and working during the day selling tickets over the phone for the Seattle Opera. The money he earned selling opera tickets he spent on beer and international phone cards. Then he cut down on beer and moved into the hotel that had my name. That kind of love scared the hell out of me. The kind of love that makes a person cut down on beer and move into a hotel just because of its name.

When he called it was nearly midnight for me but early morning for him. I lay on my stomach on the ugly gray carpet of the house that I grew up in, the phone cord stretched to the front door so I could blow cigarette smoke through the wire screen. I imagined him sitting with his face to the wall, ignoring the other residents as they tramped along the hallway. I imagined he still looked a little homeless. JFK once stayed here, he told me, Elvis stayed here. But now the cage elevators were breaking down twice, three times a week, and it was fourteen flights of stairs to the room that housed his unrefrigerated forties and his stolen desk.

His two favorite topics of conversation were the Lesser Prairie Chicken and a vending machine in Fremont that stood alone in the middle of a vacant block. The vending machine had an unlabeled mystery button underneath all of the labeled buttons for the usual drinks. He liked to speculate about what kind of soda would be dispensed if he were to push the mystery button. Would it be Tab or would it be Mr. Pibb? He rattled off a list of dead cola brands from his childhood, most of which I didn't recognize because his childhood was eleven years earlier than mine and on the other side of the world.

I bet it's Tab, he finally said. He had turned the vending machine into a time traveling device. He wanted a Tab summer. He wanted it to be 1982 in Atlanta, Georgia, before the methadone trips to Mexico and the minor prison stints for DUI. He wanted to be on his uncle's farm, raising Lesser 
Prairie Chickens. He wanted to be anywhere but Seattle, selling tickets for the opera.

One night he called and told me he'd gone to Fremont. He'd pushed the mystery button on the vending machine at the end of the world.

And you know what I got?

What'd you get? I asked.

Fucking Sprite.

And Atlanta, Georgia in 1982 was bleached-out and unreachable, and he and I had one less thing to talk about. 